\title{
PENGARUH BABY SPA TERHADAP KENAIKAN BERAT BADAN BAYI DI RUMAH SEHAT KITA PURWOKERTO
}

\author{
Wulan Margiana ${ }^{1}$, Ima Syamrotul Muflihah ${ }^{2}$ \\ ${ }^{I}$ Fakultas Ilmu Kesehatan, Universitas Muhammadiyah Purwokerto \\ ${ }^{2}$ Fakultas Ilmu Kesehatan, Universitas Muhammadiyah Purwokerto \\ email: wmargiana@gmail.com
}

\begin{abstract}
Baby Spa is one of the physiotherapy in infants and can stimulate baby motor movement. Subject in this are term infants aged 1-3 months, who were massaged 15 minutes, 2 times a week for 6 weeks also gained 50\% more weight than control. The purpose of this study was to determine the effect of baby spa on weight gain in infants at Rumah Sehat Kita Purwokerto. This study was conducted at Rumah Sehat Kita Purwokerto, from July to September 2016. Respondent in this study amounted to 20 babies. This research was conducted by quasy experiment (pre post one group), by measuring the baby's weight before the baby spa and after the baby spa with a distance of one month. Research result shows there are differences in infant weight gain between before and after baby spa with number Odd Ratio (OR) p value 0,001. The conclusion baby spa influence to baby's weight gain.
\end{abstract}

Keywords: Baby Spa, baby's weight gain

\section{PENDAHULUAN}

Pertumbuhan adalah perubahan bersifat kuantitatif yaitu bertambahnya jumlah, ukuran, dimensi tingkat sel, organ, maupun individu yang bisa diukur dengan berat (gram, pound, kilogram) ukuran panjang ( $\mathrm{cm}$, meter). Faktor-faktor yang mempengaruhi pertumbuhan yaitu faktor internal (genetic) dan factor eksternal (lingkungan) salah satunya stimulasi ( Soetijiningsih, 2015).

Stimulasi atau rangsangan yang baik untuk anak dapat dibettikan oleh orangtua untuk perkembangan potensinya secara maksimal. Faktor yang berhubungan dengan tumbuh kembang anak yaitu nutrisi yang tercukupi. Lingkungan yang mendukung merupakan dasar untuk tumbuh kembang anak. Selain itu dari segi personal anak dapat diberikan stimulasi. Salahsatu bentuk stimulasi yang umum di lakukan orangtua untuk bayi adalah rangsangan taktil dalam untuk pijat bayi (Adriana, 2013)

Pijat adalah terap sentuh paling tua dan paling popular. Pijat adalah seni perawatan kesehatan dan pengobatan yang telah dipraktekkan berabad-abad yang lalu. Sentuhan dan pijat pada bayi segera setelah lahir merupakan kontak tubuh berkelanjutan yang diperlukan bayi untuk mempertahankan rasa aman (Roesli, 2008).

Baby Spa merupakan salah satu fisioterapi pada bayi dan dapat merangsang gerakan motorik bayi. Dengan bermain air, otot-otot bayi akan berkembang dengan sangat baik, persendian tumbuh secara optimal, pertumbuhan badan meningkat, dan tubuh pun menjadi lentur. Dengan berenang gerakan didalam air semua anggota tubuh bayi akan terlatih, karena seluruh anggota tubuh digerakkan mulai dari kaki, tangan hingga kepala walaupun belum sempurna. Selain itu kemampuan mengontrol otot bayi akan lebih 
meningkat karena pada saat berenang didalam air efek gravitasi sangat rendah sehingga memungkinkan bayi untuk bergerak lebih banyak dan semua otot pun dapat bekerja dengan optimal(Yahya,2011).

Menurut Penelitian yang dilakukan oleh Prof. T. Field dan Scafidi (1986 dan 1990) menunjukkan bahwa 20 bayi prematur (berat badan 1280 dan 1176 gram), yang dipijat $3 \mathrm{x}$ 15 menit selama 10 hari, mengalami kenaikan berat badan perhari 20\% - 47\% lebih banyak dari yang tidak dipijat. Penelitian pada bayi cukup bulan yang berusia 1-3 bulan, yang dipijat 15 menit, 2 kali seminggu selama 6 minggu juga didapatkan kenaikan berat badan 50\% yang lebih dari kontrol (Riksani, 2012). Penelitian ini dilakukan untuk mengetahui Pengaruh Baby spa dengan kenaikan berat badan bayi di Rumah sehat kita Purwokerto.

\section{METODOLOGI PENELITIAN}

Penelitian ini di lakukan di Rumah Sehat Kita Purwokerto, mulai bulan Juli sampai dengan September 2016. Sampel penelitian berjumlah 20 bayi. Dengan metode Quasy eksperiman (pre post one group), dengan cara mengukur berat badan bayi sebelum dan setelah dilakukan baby dengan ajarak 1 bulan.

\section{HASILDAN PEMBAHASAN}

\section{a. Karakteristik Responden}

\section{Umur Bayi}

Tabel 1. Distribusi Frekuensi Umur Bayi

\begin{tabular}{ccc}
\hline Umur/bulan & $\mathbf{N}$ & $\mathbf{\%}$ \\
\hline 6 & 5 & 25.0 \\
7 & 4 & 20.0 \\
8 & 2 & 10.0 \\
10 & 2 & 10.0 \\
11 & 4 & 20.0 \\
12 & 3 & 15.0 \\
\hline
\end{tabular}

Berdasarkan pada tabel distribusi frekuensi diatas pada penelitian tentang pengaruh Baby Spa terhadap kenaikan berat badan bayi terdapat umur bayi terbanyak pada usia 6 bulan yaitu sebanyak 5 balita (25\%). Bayi merupakan anak dengan rentang usia 0-12 bulan. Masa bayi merupakan masa pertama kehidupan kritis. Pada masa ini bayi akan mengalami adaptasi terhadap lingkungan. Perubahan sirkulasi darah serta organ- organ tubuh mulai berfungsi (Perry \& Pooter, 2005).

\section{Jenis Kelamin}

Tabel 2 Distribusi frekuensi jenis kelamin

\begin{tabular}{ccc}
\hline Jenis Kelamin & $\mathbf{N}$ & $\mathbf{\%}$ \\
\hline laki-laki & 9 & 45.0 \\
Perempuan & 11 & 55.0 \\
\hline
\end{tabular}

Berdasarkan tabel distribusi frekuensi diatas didapatkan hasil rata-rata jenis kelamin pada penelitian ini adalah perempuan yaitu sebanyak 11 balita (55\%).

\section{b. Pengaruh baby Spa terhadap Kenaikan berat badan bayi}

Tabel 3 Pengaruh baby spa terhadap kenaikan berat badan bayi

\begin{tabular}{ccc}
\hline Variabel & $\begin{array}{c}\text { Mean } \\
\text { SD }\end{array}$ & $\begin{array}{c}\text { P } \\
\text { Value }\end{array}$ \\
\cline { 1 - 2 } Sebelum Baby Spa & 8.0250 & \\
\cline { 1 - 2 } Sesudah baby Spa & $\begin{array}{c}8.8530 \\
\end{array}$ & \multirow{2}{*}{0,001} \\
& Selisih & \\
& $: 0.828$ & \\
\hline
\end{tabular}

Berdasarkan tabel di atas terdapat perbedaan peningkatan berat badan bayi antara sebelum dilakukan baby spa dengan sesudah dilakukan baby spa. Pengukuran berat badan dilakukan dalam kurun waktu 1 bulan setelah dilakukan baby spa. Nilai $p$ 
Pembahasan Pengaruh Baby Spa Terhadap Kenaikan Berat Badan Bayi

Hasil penelitian menujukan bahwa baby spa berpengaruh terhadap kenaikan berat badan bayi di Rumah Sehat Kita Purwokerto $(p=0,001)$. Temuan penelitian menunjukkan hasil yang relevan dengan penelitian Sumini at all, yang berjudul pengaruh pijat bayi terhadap pertambahan berat badan bayi di Desa Karang Wasen Kecamatan Jiwan Kabupaten Madiun dengan hasil ada pengaruh pijat bayi terhadap pertambahan berat badan bayi usia 1-6 bulan di Desa Karang Wasen Kecamatan Jiwen Kabupaten Madiun. Dari hasil uji t ber[asangan tersebut terlihat bahwa nilai signifikan keabsahan sebesar 0,00 Keputusan uji statistic $\mathrm{Ha}$ diterima bila $\mathrm{p}<0,05$ Maka dapat disimpulkan $0,00<0,05$, artinya ada pengaruh pijat bayi terhadap pertumbuhan berat badan bayi usia 1-6 bulan di Desa Karang Wasen Kecamatan Jiwan Kabupaten Madiun.

Hal ini sesuai dengan penelitian yang dilakukan oleh Tri dkk, yang menunjukan bahwa uji mann whitney didapatkan $p$ value sebesar 0,01 $(\mathrm{p}<0,05)$ sehingga pemberian terapi pijat berpengaruh terhadap peningkatan berat badan sesuai dengan hasil penelitian Sumini at all dan Tri Sasmi Irva at all bahwa Baby Spa berpengaruh terhadap peningkatan berat badan bayi.

\section{SIMPULAN DAN SARAN}

\section{a.Simpulan}

Sebagian besar karakteristik umur usia 6 bulan yaitu sebanyak 5 balita (25\%). terdapat perbedaan peningkatan berat badan bayi antara sebelum dilakukan baby spa dengan sesudah dilakukan baby spa yaitu dengan nilai $p$ velue 0,001 . Sehingga dapat disimpulkan bahwa baby spa berpengaruh terhadap kenaikan berat badan bayi.

\section{b.Saran}

Bagi ibu agar rutin melakukan baby spa pada bayi di klinik maupun dirumah agar dapat mengoptimalkan pertumbuhan dan perkembangan bayi.

\section{DAFTAR PUSTAKA}

Adriana, D. 2013. Tumbuh kembang \& Terapi bermain pada anak. Jakarta: Penerbit Salemba Medika.

Potter,P, A.\& Perry A,G. 2005. Fundamental Keperawatan Konsep Proses dan Praktik Alih bahasa: Monica ester. Jakarta: EGC.

Riksani, E. 2012. Mensikapi Asi Eksklusif pada Ibu Bekerja. Jakarta: Salemba Medika.

Roesli, U. 2008. Pedoman Pijat Bayi Prematur \& Bayi Usia 0-3 Bulan. Jakarta: Trubus griwidya.

Soetjiningsih, Gde Ranuh IGN. 2015. Tumbuh Kembang Anak. Jakarta: EGC.

Sumini, at all. 2012. Pertambahan Berat Badan Bayi Di Desa Karang Wasen Kecamatan Jiwan Kabupaten Madiun.

Tri, $d k k$. 2014. Peengaruh Terapi Pijat terhadap Peningkatan Berat bandan bayi. JOMPSIK Vol.1 No 2. Oktober 2014.

Yahya, N. 2011. Spa Bayi \& Anak. Solo : Dipl. CIBTAC 